\title{
PENGARUH TINGKAT SOSIAL EKONOMI ORANG TUA TERHADAP KARIES ANAK DI TK HANG TUAH BITUNG
}

\author{
${ }^{1}$ Rebecca A. Ngantung \\ ${ }^{2}$ Damajanty H. C. Pangemanan \\ ${ }^{3}$ Paulina N. Gunawan
}

\author{
${ }^{1}$ Kandidat Skripsi Program Studi Pendidikan Dokter Gigi Fakultas Kedokteran \\ ${ }^{2}$ Bagian Fisiologi Fakultas Kedokteran \\ ${ }^{3}$ Program Studi Pendidikan Dokter Gigi Fakultas Kedokteran \\ Universitas Sam Ratulangi Manado \\ Email:naudinarebeca@yahoo.co.id
}

\begin{abstract}
Dental caries is a major problem in children's mouth cavity. The damage of the primary teeth spreads faster, expands more, and worse than permanent teeth. Socioeconomics status is one of the factors that affect health status. In order to meets the need of life and to get the desired health service, the higher socioeconomic groups have more chance than the lower socioeconomic groups. This study aimed to find out the influence of parental socioeconomic to children's caries in Hang Tuah Bitung Kindergarten. This was an analytical study using a cross sectional design. The population consisted of students of Hang Tuah Bitung Kindergarten with a total of 72 children. Samples were 52 students obtauned by using total sampling method. The primary data collection used def-t examination and parental identity checked from. The statistical analysis was perfomed by using Spearman's test. The results showed that there was no effect of parents' employment of parents to children dental caries ( $p=0.092)$; there was no effect of parents' education to children dental caries $(p=0.425)$; no effect of parents' income to children dental caries $(p=0.164)$; there was no effect of the number of family members to children dental caries $(\mathrm{p}=0.119)$. Conclusion: There was no effect of socioeconomic status of the parents to children dental caries.
\end{abstract}

Keywords: socioeconomic level, occupation, education, income, caries

\begin{abstract}
Abstrak: Karies merupakan masalah utama di rongga mulut anak. Kerusakan gigi sulung lebih cepat menyebar, meluas, dan lebih parah dari pada gigi permanen. Status sosial ekonomi merupakan salah satu faktor yang memengaruhi status kesehatan, sebab dalam memenuhi kebutuhan hidup dan untuk mendapatkan tempat pelayanan kesehatan yang diinginkan lebih memungkinkan bagi kelompok sosial ekonomi tinggi dibandingkan dengan kelompok sosial ekonomi rendah. Tujuan penelitian ini yaitu untuk mengetahui pengaruh tingkat sosial ekonomi orang tua terhadapkaries anak di TK Hang Tuah Bitung.Penelitian ini merupakan penelitian yang bersifat analitik dengan menggunakan metode cross sectional. Populasi penelitian ini ialah murid TK Hang Tuah Bitung yang berjumlah 72 orang. Sampel yang diteliti 52 anak dengan menggunakan total sampling. Metode pengambilan data secara primer yaitu dengan pemeriksaan def-t dan formulir pemeriksaan identitas orang tua. Analisis statistik dilakukan dengan menggunakan uji Spearman. Hasil penelitian diperoleh, tidak ada pengaruh tingkat pekerjaan orang tua terhadap karies gigi anak $(\mathrm{p}=0,092)$, tidak ada pengaruh tingkat pendidikan orang tua terhadap karies gigi anak $(\mathrm{p}=0,425)$, tidak ada pengaruh tingkat pendapatan orang tua terhadap karies gigi anak $(\mathrm{p}=0,164)$, tidak ada pengaruh banyaknya anggota keluarga orang tua terhadap karies gigi anak $(p=0,119)$. Simpulan: Tidak terdapat pengaruh tingkat sosial ekonomi orang tua terhadap karies gigi anak.
\end{abstract}

Kata kunci : tingkat sosial ekonomi, pekerjaan, pendidikan, pendapatan, karies. 
Perilaku hidup sehat dapat dipengaruhi oleh sosial ekonomi seseorang. ${ }^{1}$ Beberapa faktor yang memengaruhi sosial ekonomi yaitu pekerjaan, pendidikan, pendapatan, serta banyaknya anggota keluarga. Pekerjaan menentukan status sosial ekonomi karena dari bekerja segala kebutuhan akan dapat terpenuhi. Pendidikan yang lebih tinggi memiliki sifat yang positif tentang kesehatan dan mempromosikan perilaku hidup sehat. ${ }^{2}$ Pendapatan mempunyai pengaruh langsung pada perawatan medis, jika pendapatan meningkat biaya untuk perawatan kesehatanpun ikut meningkat. ${ }^{3}$ Kelurga merupakan fondasi awal untuk membangun kehidupan sosial ekonomi secara luas menjadi lebih baik, dimana peran aktif dari keluarga terhadap perkembangan seorang anak sangat diperlukan dalam memberikan dasar pendidikan, sikap, dan keterampilan dasar, mematuhi peraturan dan menanamkan kebiasaan-kebiasaan. ${ }^{4}$

Kesehatan gigi dan mulut sering tidak menjadi prioritas bagi sebagian orang, padahal gigi dan mulut merupakan "pintu gerbang" masuknya kuman dan bakteri sehingga dapat mengganggu kesehatan organ tubuh lainnya. ${ }^{5}$ Menurut Riset Kesehatan Dasar 2013, prevalensi nasional karies aktif ialah 43,4\%. Sebanyak 14 provinsi memiliki prevalensi karies aktif diatas prevalensi Nasional yaitu Riau, Jambi, Sumatera Selatan, Bangka Belitung, Di Yogyakarta, Jawa Timur, Kalimantan Barat, Kalimantan Tengah, Kalimantan Selatan, Kalimantan Timur, Sulawesi Utara, Sulawesi Tengah, Sulawesi Tenggara, dan Maluku. Menurut data tingkat provinsi di Indonesia, prevalensi karies aktif tertinggi (lebih dari 50\%) ditemukan di Jambi (56,1\%), Kalimantan Barat dan Sulawesi Utara(57,2\%), Maluku (54,4\%), Riau (53,3\%), Lampung (54,9\%). Yogyakarta (52,3\%), Bangka Belitung (50,8\%), Kalimantan Selatan (50,7\%) Kalimantan Timur (50,6\%), Jawa Barat dan Sulawesi Selatan masing-masing 50,4\%. Sedangkan sepuluh provinsi dengan prevalensi pengalaman karies tertinggi, adalah Bangka Belitung (86,8\%), Kalimantan Selatan (84,7\%), Sulawesi Utara (82,8\%), DI Yogyakarta (78,9\%), Kalimantan Barat (78,7\%), Kalimantan Timur (76,6\%) dan Kalimantan Tengah (76,4), Jambi (77,9\%), Maluku (77,5\%), dan Jawa Timur (76,2\%). ${ }^{6}$

Karies gigi merupakan masalah yang signifikan, karena diperparah dengan tingkat sosial ekonomi yang rendah serta malnutrisi.
Karies gigi lebih sering dijumpai pada anakanak dari keluarga dengan tingkat sosial ekonomi yang rendah, ibu/bapa tunggal, atau orangtua dengan tingkat pendidikan rendah. ${ }^{7}$ Usia merupakan faktor yang sangat mempengaruhi terjadinya karies gigi. Masalah karies gigi masih banyak dikeluhkan baik oleh anak-anak maupun dewasa dan tidak bisa dibiarkan hingga parah karena akan mempengaruhi kualitas hidup dimana mereka akan mengalami, rasa sakit, ketidaknyamanan, cacat, infeksi akut dan kronis, ganguan makan dan tidur serta memiliki risiko tinggi untuk dirawat di rumah sakit serta puskesmas, yang menyebabkan biaya pengobatan tinggi dan berkurangnya waktu belajar di sekolah. ${ }^{5}$

Seperti yang telah disebutkan diatas bahwa karies gigi merupakan masalah kesehatan masyarakat yang serius, oleh karena itu memerlukan keterlibatan semua pihak untuk mengatasinya. Keluarga memainkan peranan yang penting dalam kariesgigi anak karena dapat menjadi orang pertama yang mengetahui adanya kelainan pada anak tersebut. Anak yang mengalami karies gigi perlu dirawat segera, agar masalah lebih parah yang dapat mengganggu kualitas hidup mereka dapat dihindari. Oleh karena itu, dalam penelitian ini orang tua dilibatkan untuk mendapatkan persepsi mengenai kesehatan gigi anaknya serta masalah yang timbul akibat kerusakan gigi yang dialami anaknya.

TK Hang Tuah Bitung merupakan sekolah TK swasta yang terletak di Kota Bitung, kelurahan Bitung Tengah, kecamatan Maesa, Provinsi Sulawesi Utara. TK Hang Tuah ini memiliki murid dengan berbagai macam status sosial ekonomi, baik yang berstatus sosial menengah kebawah, menengah maupun menengah keatas. Penelitian ini dilakukan pada anak TK, karena karies sering terjadi pada anak di usia prasekolah. Berdasarkan hal tersebut, peneliti tertarik untuk mengetahui apakah ada pengaruh tingkat sosial ekonomi orang tua terhadap karies gigi anak di TK Hang Tuah Bitung.

\section{BAHAN DAN METODE PENELITIAN}

Metode penelitian yang digunakan ialah analitik dengan pendekatan potong lintang. Penelitian ini dilaksanakan pada tanggal 10-11 September 2015. Populasi penelitian ini ialah seluruh siswa TK Hang Tuah Bitung yang berjumlah 72 siswa. Pengambilan sampel dalam penelitian ini menggunakan total sampling. 
Variabel penelitian ini yaitu sosial ekonomi orang tua dan karies anak. Sosial ekonomi orang tua dinilai dari tingkat pekerjaan, tingkat pendidikan, tingkat pendapatan dan banyaknya anggota keluarga. Pengukuran karies gigi diukur dengan menggunakan indeks def-t. Data diolah dan ditampilkan dalam bentuk tabel dengan menggunakan uji statistik Spearman.

\section{HASIL PENELITIAN}

Hasil penelitian menunjukan distribusi responden dengan karakteristik sebagai berikut:

Tabel 1. Distribusi responden berdasarkan usia

\begin{tabular}{ccc}
\hline $\begin{array}{c}\text { Usia } \\
\text { (tahun) }\end{array}$ & $\mathrm{n}$ & $\%$ \\
\hline 3 & 3 & 5,8 \\
4 & 16 & 30,8 \\
5 & 33 & 63,4 \\
\hline Jumlah & 52 & 100 \\
\hline
\end{tabular}

Tabel 2. Distribusi responden berdasarkan jenis kelamin

\begin{tabular}{ccc}
\hline Jenis Kelamin & $\mathrm{n}$ & $\%$ \\
\hline Laki - Laki & 32 & 61,5 \\
Perempuan & 20 & 38,5 \\
\hline Jumlah & 52 & 100 \\
\hline
\end{tabular}

Tabel 3. Distribusi responden berdasarkan tingkat pekerjaan orang tua

\begin{tabular}{lcc}
\hline $\begin{array}{l}\text { Tingkat Pekerjaan } \\
\quad \text { Orang Tua }\end{array}$ & $\mathrm{n}$ & $\%$ \\
\hline Rendah & 7 & 13,5 \\
Menengah & 25 & 48 \\
Tinggi & 20 & 38,5 \\
\hline \multicolumn{1}{c}{ Jumlah } & 52 & 100 \\
\hline
\end{tabular}

Tabel 4. Distribusi responden berdasarkan tingkat pendidikan orang tua

\begin{tabular}{lcc}
\hline $\begin{array}{l}\text { Tingkat Pendidikan } \\
\quad \text { Orang Tua }\end{array}$ & $\mathrm{n}$ & $\%$ \\
\hline Rendah & 1 & 1,9 \\
Menengah & 36 & 69,2 \\
Tinggi & 15 & 28,8 \\
\hline \multicolumn{1}{c}{ Jumlah } & 52 & 100 \\
\hline
\end{tabular}

Tabel 5. Distribusi responden berdasarkan tingkat pendapatan orang tua

\begin{tabular}{lcc}
\hline $\begin{array}{l}\text { Tingkat Pendapatan } \\
\quad \text { Orang Tua }\end{array}$ & $\mathrm{n}$ & $\%$ \\
\hline Rendah & 23 & 44,2 \\
Menengah & 14 & 27 \\
Tinggi & 15 & 28,8 \\
\hline \multicolumn{1}{c}{ Jumlah } & 52 & 100 \\
\hline
\end{tabular}

Tabel 6. Distribusi responden berdasarkan banyaknya anggota keluarga

\begin{tabular}{lcc}
\hline $\begin{array}{c}\text { Banyaknya Anggota } \\
\quad \text { Keluarga }\end{array}$ & $\mathrm{n}$ & $\%$ \\
\hline Kecil & 33 & 63,5 \\
Sedang & 19 & 36,5 \\
Besar & 0 & 0 \\
\hline \multicolumn{1}{c}{ Jumlah } & 52 & 100 \\
\hline
\end{tabular}

Tabel 7. Distribusi responden berdasarkan tingkat karies

\begin{tabular}{lcc}
\hline \multicolumn{1}{c}{ Tingkat Karies } & $\mathrm{n}$ & $\%$ \\
\hline Sangat Tinggi & 18 & 35 \\
Tinggi & 5 & 10 \\
Sedang & 8 & 15 \\
Rendah & 8 & 15 \\
Sangat Rendah & 13 & 25 \\
\hline \multicolumn{1}{c}{ Jumlah } & 52 & 100 \\
\hline
\end{tabular}

Tabel 8. Distribusi responden berdasarkan tingkat pekerjaan dan tingkat karies

\begin{tabular}{|c|c|c|c|c|c|c|c|c|c|c|c|c|c|}
\hline \multirow{3}{*}{$\begin{array}{c}\text { Tingkat } \\
\text { Pekerjaan } \\
\text { Orang } \\
\text { Tua }\end{array}$} & \multicolumn{10}{|c|}{ Tingkat Karies } & \multirow{3}{*}{$\mathrm{n}$} & \multirow{3}{*}{$\%$} & \multirow{3}{*}{$\mathrm{p}$} \\
\hline & \multicolumn{2}{|c|}{$\begin{array}{l}\text { Sangat } \\
\text { Tinggi }\end{array}$} & \multicolumn{2}{|c|}{ Tinggi } & \multicolumn{2}{|c|}{ Sedang } & \multicolumn{2}{|c|}{ Rendah } & \multicolumn{2}{|c|}{$\begin{array}{l}\text { Sangat } \\
\text { Rendah }\end{array}$} & & & \\
\hline & $\mathrm{n}$ & $\%$ & $\mathrm{n}$ & $\%$ & $\mathrm{n}$ & $\%$ & $\mathrm{n}$ & $\%$ & $\mathrm{n}$ & $\%$ & & & \\
\hline Rendah & 3 & 43 & 1 & 14 & 1 & 14 & 2 & 29 & 0 & 0 & 7 & 13.5 & \\
\hline Menengah & 12 & 48 & 1 & 4 & 2 & 8 & 3 & 12 & 7 & 28 & 25 & 48 & \\
\hline Tinggi & 3 & 15 & 3 & 15 & 5 & 25 & 3 & 15 & 6 & 30 & 20 & 38.5 & 0,092 \\
\hline Jumlah & 18 & 35 & 5 & 10 & 8 & 15 & 8 & 15 & 13 & 25 & 52 & 100 & \\
\hline
\end{tabular}


Ngantung, Pangemanan, Gunawan: Pengaruh tingkat sosial...

Tabel 9. Distribusi responden berdasarkan tingkat pendidikan dan tingkat karies

\begin{tabular}{|c|c|c|c|c|c|c|c|c|c|c|c|c|c|}
\hline \multirow{3}{*}{$\begin{array}{c}\text { Tingkat } \\
\text { Pendidikan } \\
\text { Orang } \\
\text { Tua } \\
\end{array}$} & \multicolumn{10}{|c|}{ Tingkat Karies } & \multirow{3}{*}{$\mathrm{n}$} & \multirow{3}{*}{$\%$} & \multirow{3}{*}{$\mathrm{p}$} \\
\hline & \multicolumn{2}{|c|}{$\begin{array}{l}\text { Sangat } \\
\text { Tinggi } \\
\end{array}$} & \multicolumn{2}{|c|}{ Tinggi } & \multicolumn{2}{|c|}{ Sedang } & \multicolumn{2}{|c|}{ Rendah } & \multicolumn{2}{|c|}{$\begin{array}{l}\text { Sangat } \\
\text { Rendah }\end{array}$} & & & \\
\hline & $\mathrm{n}$ & $\%$ & $\mathrm{n}$ & $\%$ & $\mathrm{n}$ & $\%$ & $\mathrm{n}$ & $\%$ & $\mathrm{n}$ & $\%$ & & & \\
\hline Rendah & 1 & 100 & 0 & 0 & 0 & 0 & 0 & 0 & 0 & 0 & 1 & 1,9 & \\
\hline Menengah & 13 & 36 & 3 & 8 & 6 & 17 & 5 & 14 & 9 & 25 & 36 & 69,2 & \\
\hline Tinggi & 4 & 27 & 2 & 13 & 2 & 13 & 3 & 20 & 4 & 27 & 15 & 28,8 & $0,4 \angle 5$ \\
\hline Jumlah & 18 & 35 & 5 & 10 & 8 & 15 & 8 & 15 & 13 & 25 & 52 & 100 & \\
\hline
\end{tabular}

Tabel 10. Distribusi responden berdasarkan tingkat pendapatan orang tua dan tingkat karies

\begin{tabular}{|c|c|c|c|c|c|c|c|c|c|c|c|c|c|}
\hline \multirow{3}{*}{$\begin{array}{c}\text { Tingkat } \\
\text { Pendapatan } \\
\text { Orang } \\
\text { Tua } \\
\end{array}$} & \multicolumn{10}{|c|}{ Tingkat Karies } & \multirow{3}{*}{$\mathrm{n}$} & \multirow{3}{*}{$\%$} & \multirow{3}{*}{$\mathrm{p}$} \\
\hline & \multicolumn{2}{|c|}{$\begin{array}{l}\text { Sangat } \\
\text { Tinggi }\end{array}$} & \multicolumn{2}{|c|}{ Tinggi } & \multicolumn{2}{|c|}{ Sedang } & \multicolumn{2}{|c|}{ Rendah } & \multicolumn{2}{|c|}{$\begin{array}{l}\text { Sangat } \\
\text { Rendah }\end{array}$} & & & \\
\hline & $\mathrm{n}$ & $\%$ & $\mathrm{n}$ & $\%$ & $\mathrm{n}$ & $\%$ & $\mathrm{n}$ & $\%$ & $\mathrm{n}$ & $\%$ & & & \\
\hline Rendah & 11 & 48 & 2 & 9 & 2 & 9 & 4 & 17 & 4 & 17 & 23 & 44,2 & \\
\hline Menengah & 4 & 29 & 1 & 7 & 2 & 14 & 2 & 14 & 5 & 36 & 14 & 27 & \\
\hline Tinggi & 3 & 20 & 2 & 13 & 4 & 27 & 2 & 13 & 4 & 27 & 15 & 28,8 & 0,164 \\
\hline Jumlah & 18 & 35 & 5 & 10 & 8 & 15 & 8 & 15 & 13 & 25 & 52 & 100 & \\
\hline
\end{tabular}

Tabel 11. Distribusi responden berdasarkan banyaknya anggota keluarga dan tingkat karies

\begin{tabular}{|c|c|c|c|c|c|c|c|c|c|c|c|c|c|}
\hline \multirow{3}{*}{$\begin{array}{c}\text { Banyaknya } \\
\text { Anggota } \\
\text { Keluarga }\end{array}$} & \multicolumn{10}{|c|}{ Tingkat Karies } & \multirow{3}{*}{$\mathrm{n}$} & \multirow{3}{*}{$\%$} & \multirow{3}{*}{$\mathrm{P}$} \\
\hline & \multicolumn{2}{|c|}{$\begin{array}{l}\text { Sangat } \\
\text { Tinggi }\end{array}$} & \multicolumn{2}{|c|}{ Tinggi } & \multicolumn{2}{|c|}{ Sedang } & \multicolumn{2}{|c|}{ Rendah } & \multicolumn{2}{|c|}{$\begin{array}{l}\text { Sangat } \\
\text { Rendah }\end{array}$} & & & \\
\hline & $\mathrm{n}$ & $\%$ & $\mathrm{n}$ & $\%$ & $\mathrm{n}$ & $\%$ & $\mathrm{n}$ & $\%$ & $\mathrm{n}$ & $\%$ & & & \\
\hline Kecil & 14 & 43 & 3 & 9 & 4 & 12 & 6 & 18 & 6 & 18 & 33 & 63,5 & \\
\hline Sedang & 4 & 21 & 2 & 10,5 & 4 & 21 & 2 & 10,5 & 7 & 37 & 19 & 36,5 & \\
\hline Besar & 0 & 0 & 0 & 0 & 0 & 0 & 0 & 0 & 0 & 0 & 0 & 0 & 119 \\
\hline Jumlah & 18 & 35 & 5 & 10 & 8 & 15 & 8 & 15 & 13 & 25 & 52 & 100 & \\
\hline
\end{tabular}

\section{BAHASAN}

Pada penelitian ini uji statistik yang digunakan yaitu uji Spearman. Penelitian ini dilakukan di TK Hang Tuah Bitung dengan jumlah sampel seluruhnya sebanyak 52 orang. Sesuai dengan tujuan dari penelitian ini dilakukan untuk melihat pengaruh sosialekonomi orang tua terhadap karies gigi anak ditinjau dari tingkat pekerjaan orang tua, tingkatpendidikan orang tua, tingkat pendapatan orangtua dan banyaknya anggota keluarga.

Dari hasil penelitian diketahui karakteristik responden yang tingkat karies sangat tinggi pada responden berusia 5 tahun dan berjenis kelamin laki-laki. Karies meningkat seiring dengan bertambahnya usia, gigi yang paling akhir erupsi lebih rentan terhadap karies. Hal ini disebabkan karena sulitnya membersihkan gigi yang sedang erupsi. Dilihat dari jenis kelamin, karies pada anak laki-laki lebih tinggi dari pada anak perempuan. Hasil penelitian oleh Sihombing ${ }^{8}$ di Medan menunjukkan bahwa pengalaman karies lebih tinggi pada perempuan dari pada laki-laki selama periode anak-anak sampai remaja.

Berdasarkan distribusi responden tingkat pekerjaan orang tua menunjukkan, sebagian besar responden memiliki orang tua yang tingkat pekerjaan menengah yaitu berjumlah 25 responden (48\%). Pekerjaan 
ialah simbol status seseorang di masyarakat yang merupakan jembatan untuk memperoleh uang dalam memenuhi kebutuhan hidup dan untuk mendapatkan tempat hidup dan untuk mendapatkan tempat pelayanan kesehatan yang diinginkan. Jadi semakin baik jenis pekerjaan seseorang maka semakin terpenuhi pula kebutuhan hidup dan kesehatan keluarga. ${ }^{9}$

Berdasarkan distribusi responden tingkat pendidikan didapatkan bahwa, sebagian besar responden memiliki orang tua dengan tingkat pendidikan menengah yaitu 36 orang $(69,2 \%)$. Semakin tinggi tingkat pendidikan formal seseorang, maka semakin baik pengetahuan dan sikap perilaku hidup sehat, bahkan semakin mudah untuk memperoleh pekerjaan sehingga semakin banyak pula penghasilan yang diperoleh untuk memenuhi kebutuhan kesehatan. Sebaliknya, pendidikan yang kurang akan menghambat perkembangan sikap seseorang terhadap nilai-nilai yang baru dikenal. $^{10}$

Berdasarkan distribusi responden tingkat pendapatan orang tua menunjukkan, sebagian besar orang tua responden memiliki tingkat pendapatan rendah yaitu berjumlah 23 orang (44,2\%). Anak-anak dengan orang tua yang berpenghasilan cukup, mempunyai kesempatan untuk memperoleh pelayanan kesehatan. Orang tua dengan penghasilan yang memadai akan memungkinkan memberikan pelayanan kesehatan yang lebih baik kepada anaknya. Orang dengan kemampuan ekonomi kurang akan kesulitan untuk memenuhi kebutuhan pokoknya, sehingga akan sulit memberikan pelayanan kesehatan untuk keluarganya. ${ }^{11}$

Distribusi responden berdasarkan banyaknya anggota keluarga menunjukkan bahwa sebagian besar responden memiliki keluarga yang tergolong dalam kategori keluarga kecil yaitu berjumlah 33 orang (63,5\%). Banyaknya anggota keluarga akan sangat memengaruhi pengeluaran dalam sebuah keluarga. Semakin besar ukuran sebuah keluarga maka akan semakin besar pengeluaran atau anggaran yang di butuhkan, jika pendapatan keluarga kecil maka distribusi pengeluaran untuk masing- masing personal akan semakin kecil.

Dari hasil penelitian diketahui, presentase responden yang mengalami karies gigi dengan tingkat karies sangat tinggi paling banyak terdapat pada tingkat pekerjaan orang tua responden yang menengah. Hasil uji statistik menunjukkan tidak ada pengaruh pekerjaan orang tua terhadap karies gigi anak. Hal ini disebabkan karena pernyataan dari orang tua responden bahwa, pekerjaan ayah yang rata-ratanya pada tingkat pekerjaan menengah sebagai nelayan dan tukang membuat sebagian besar ibu responden juga membantu mencari tambahan penghasilan sehingga terlalu sibuk dengan pekerjaan masing-masing, akhirnya tidak begitu memerhatikan kebersihan gigi dan mulut anak secara maksimal dan juga tidak mengontrol gigi anak ke puskesmas, rumah sakit atau dokter gigi. Hasil yang berbeda dilakukan oleh Sihite ${ }^{9}$ di SD Negeri Pancur Batu dan SD Swasta Santo Thomas 5 Medan, menunjukkan terdapat hubungan yang bermakna antara pekerjaan dengan bebas karies gigi anak $(p=0,001)$.

Hasil penelitian menunjukkan, presentase responden yang mengalami karies gigi dengan tingkat karies sangat tinggi paling banyak terdapat pada tingkat pendidikan orang tua responden yang rendah. Hasil uji statistik menunjukkan tidak ada pengaruh pendidikan orang tua terhadap karies gigi anak. Tingkat pendidikan mempresentasikan tingkat kemampuan seseorang dalam memperoleh dan memahami informasi kesehatan. Semakin tinggi tingkat pendidikan seseorang diasumsikan semakin baik tingkat pemahamannya terhadap informasi kesehatan yang diperolehnya. Permasalahannya disini adalah dari mana orang tua responden memperoleh informasi tentang pemeliharaan kebersihan gigi. Pemantauan peneliti selama proses penelitian diperoleh bahwa sebagian orang tua responden menyatakan bahwa jarang memperoleh informasi tentang cara pemeliharaan kebersihan gigi dan mulut. Hasil penelitian ini sesuai dengan penelitian Remita ${ }^{12}$ yang menyimpulkan bahwa tingkat pendidikan 
tidak berhubungan dengan kebersihan gigi anak di desa Ngasel Rejo Surabaya. Penelitian ini berbeda dengan penelitian yang dilakukan Sihite, menunjukkan dengan berdasarkan perhitungan statistik terdapat hubungan bermakna antara tingkat pendidikan orang tua dengan prevalensi bebas karies gigi anak $(\mathrm{p}=0,007) .^{9}$

Hasil penelitian menunjukkan, persentase responden yang mengalami karies gigi dengan tingkat karies sangat tinggi paling banyak terdapat pada tingkat pendapatan orang tua responden yang rendah. Hasil uji statistik menunjukkan tidak ada pengaruh pendapatan orang tua terhadap karies gigi anak. Anak-anak mempunyai kebiasaan untuk mengonsumsi makanan ringan dan makanan manis. Makanan ringan dan makanan manis dikemas dalam kemasan menarik, dijual dengan harga yang relatif murah dan mudah didapatkan. Penelitian yang dilakukan Hotl pada murid prasekolah di Inggris menyatakan bahwa konsumsi makanan manis lebih dari empat kali sehari akan meningkatkan kejadian karies. ${ }^{13}$ Anak dengan pendapatan orang tua tinggi cenderung mengonsumsi makanan kariogenik sehingga menyebabkan karies, namun seseorang dengan tingkat pendapatan yang tinggi juga ada kecenderungan untuk mendapatkan perawatan gigi yang lebih baik disbanding dengan tingkat pendapatan yang rendah. Hasil penelitian serupa dilakukan oleh Thioritz ${ }^{14}$ menunjukkan tidak ada pengaruh antara tingkat pendapatan keluarga terhadap status karies pada murid TK di Kecamatan Rappocini. Hasil penelitian yang dilakukan Susi $\mathrm{dkk}^{13}$ mendapat hasil data dengan nilai $\mathrm{p}=0,490$ yang artinya tidak ada hubungan yang bermakna antara pendapatan orang tua dengan karies gigi anak.

Hasil penelitian ini menunjukkan, persentase responden yang mengalami karies gigi dengan tingkat karies sangat tinggi paling banyak terdapat pada anggota keluarga responden yang termasuk dalam kategori kecil. Hasil uji statistik menunjukkan tidak ada pengaruh banyaknya anggota keluarga terhadap karies gigi anak. Penelitian serupa dilakukan oleh Hidayanti ${ }^{15}$ di Tasikmalaya, menunjukkan bahwa tidak ada hubungan keluarga dengan keparahan karies gigi. Ditinjau dari beban tanggungan, semakin banyak anggota keluarga maka tanggungan semakin besar pula. Selain itu semakin besar jumlah anggota, seorang anak harus berbagi perhatian yang didapat dari kedua orangnya tua dengan saudara-saudaranya sehingga orang tua tidak bisa hanya memikirkan salah satu anaknya saja. Akibatnya sulit memenuhi kebutuhan hidup anak, baik secara moral maupun material. Sebaliknya keluarga yang memiliki jumlah anggota yang lebih kecil akan memiliki tanggungan yang lebih ringan sehingga akan lebih mudah dalam memenuhi kebutuhan hidup anggota keluarganya. Dalam penelitian ini anggota keluarga yang kecil memiliki tingkat karies yang sangat tinggi. Menurut asumsi peneliti, hal ini terjadi karena orang tua yang anggota keluarganya kecil dapat memenuhi kebutuhan anak, sehingga orang tua memanjakan anak dan memberikan segala sesuatu keinginan anak, salah satu contohnya membelikan makanan-makanan kariogenik sehingga mengakibatkan tingkat karies gigi anak sangat tinggi.

\section{SIMPULAN}

1. Tidak ada pengaruh yang bermakna tingkat pekerjaan orang tua terhadap karies gigi anak di TK Hang Tuah Bitung.

2. Tidak ada pengaruh yang bermakna tingkat pendidikan orang tua terhadap karies gigi anak di TK Hang Tuah Bitung.

3. Tidak ada pengaruh yang bermakna tingkat pendapatan orang tua terhadap karies gigi anak di TK Hang Tuah Bitung.

4. Tidak ada pengaruh yang bermakna banyaknya anggota keluarga terhadap karies gigi anak di TK Hang Tuah Bitung. 
5. Tidak ada pengaruh yang bermakna sosial ekonomi orang tua terhadap karies

gigi anak di TK Hang Tuah Bitung.

\section{SARAN}

1. Bagi pemerintah diharapkan untuk lebih meningkatkan program preventif dan promotif di bidang kesehatan gigi dan mulut agar masyarakat mendapat informasi lebih mengenai cara mencegah terjadinya karies.

2. Bagi sekolah diharapkan untuk menerapkan aturan menyikat gigi setelah makan pagi di sekolah sehingga dapat mengurangi terjadinya karies gigi.

3. Bagi orang tua diharapkan lebih memerhatikan cara menyikat gigi serta dalam pembagian snack dan makanan diusahakan memberikan dengan jumlah kadar gula rendah, karena glukosa yang tinggi merupakan faktor penyebab karies.

\section{DAFTAR PUSTAKA}

1. Mulder BC, Marijn DB, Hanneke S, Erik A, Cees M. Stressors and resources mediate the association of socioeconomic position with health behavior. BMC Public Health. 2011;11:798.

2. Soekanto S. Sosiologi Suatu Pengantar. Jakarta: Rajawali Press, 2003; p.8495.

3. Nissim BD. Economic growth and its effect on public health. 2011. Diunduh dari: www.emeraldinsight.com/03068293.html

4. Diana M. Psikologi Bermain Anak Usia Dini, Jakarta: Kencana, 2010; p.86.

5. Kementrian Kesehatan Republik Indonesia. Rencana Program pelayanan Kesehatan Gigi dan Mulut, 2012; p.56.

6. Badan Penelitian dan Pengembangan Kesehatan Departemen Kesehatan Republik Indonesia. Laporan Riset Kesehatan Dasar Nasional tahun 2013. Jakarta: Departemen Kesehatan RI; 2013. p.142-43.
7. Dalia H. Efek Psikososial Karies Gigi Pada Anak Usia 3-5 Tahun yang Memiliki Karies Tinggi dan Rendah. Medan : USU. 2010. Di unduh dari : http://repository.usu.ac.id/bitstream/1 23456789/21345/5/Chapter\%20I.pdf

8. Sihombing J. Karakteristik Penderita Karies Gigi yang Berobat di Rumah Sakit Umum Dr. Pirngadi. Medan: USU. 2009. Di unduh dari:http://repository.usu.ac.id/bitstrea m/123456789/14660/1/09E01300.pdf

9. Sihite JH. Hubungan Tingkat Sosial Ekonomi Orang Tua Dengan Status Bebas Karies Pada Anak Usia 7-11 Tahun. Medan: USU. 2012.

10.Pintauli S, Hamada T. Menuju Gigi dan Mulut Sehat Pencegahan Dan Pemeliharaan. Medan: USU. 2009; p.1-6, 15-24,29-30, 70-84.

11. Soetjiningsih. Tumbuh Kembang Anak. Jakarta: EGC; 1995. p.10.

12.Remita, et al. Hubungan Antara Tingkat Pendidikan dan Pengetahuan Ibu dengan Gambaran Kebersihan Gigi di Desa Ngagel Rejo Surabaya. Fakultas Kedokteran Gigi. Surabaya: Universitas Airlangga, 2002.

13.Susi, Hafni B, Ummul A. Hubungan Status Sosial Ekonomi Orang Tua dengan Karies pada Gigi Sulung Anak Umur 4 dan 5 Tahun. Majalah Kedokteran Andalas. 2012;36(1);103.

14.Thioritz E. Pengaruh Faktor SosialEkonomi Terhadap Status Karies pada Murid Taman Kanak-Kanak Kecamatan Rappocini. Politeknik Kesehatan Makassar. Jurusan Kesehatan Gigi.2010. Di unduh dari :http://isjd.pdii.lipi.go.id/index.php/Se arch.html?act=tampil\&id=69657\&idc $=45$

15.Hidayanti. Hubungan Karakteristik Keluarga dan Kebiasaan Mengkonsumsi Makanan Kariogenik dengan Keparahan Karies Gigi pada Anak Sekolah Dasar di Kecamatan Cihideung Kota Tasikmalaya. 2005. Available from: www.biomedcentral.com/content/pdf/ 1471-2458-11-798.pdf 